\title{
Estimation of the prevalence of malocclusion on the basis of nationwide oral health examinations of pre-adolescent and adolescent students during 2012-2017
}

\author{
Mihee Hong ${ }^{\mathrm{a}}$ (1) \\ Hee-Moon Kyung ${ }^{a}$ \\ Hyo-Sang Park \\ Won-Jae $\mathrm{Yu}^{\mathrm{a}}$ \\ Seung-Hak Baek ${ }^{\mathrm{b}}$ (1)
}

${ }^{a}$ Department of Orthodontics, School of Dentistry, Kyungpook National University, Daegu, Korea

${ }^{\mathrm{b}}$ Department of Orthodontics and Dental Research Institute, School of Dentistry, Seoul National University, Seoul, Korea

\begin{abstract}
Objective: To investigate the prevalence of malocclusion with respect to grade, sex, and year among Korean pre-adolescent and adolescent students during 2012-2017. Methods: A total of 165,996 students (first grade [E1, 6-7 years of age], fourth grade [E4, 9-10 years], seventh grade [M1, 12-13 years], and tenth grade [ $\mathrm{H} 1,15-16$ years]) were selected by stratified sampling method and underwent the nationwide oral health examination performed by the Ministry of Education, Republic of Korea. The malocclusion assessments based on dentists' judgments were "no malocclusion," "needs orthodontic treatment (N-OTx)," and "under orthodontic treatment (U-OTx)." The sum of N-OTx and U-OTx cases was determined as the number of students with malocclusion. After analyzing the prevalence of malocclusion according to grade, sex, and year-by-year differences, Pearson correlation analyses and two-way analyses of variance were performed. Results: The prevalence of malocclusion was 18.7\%, which increased with the grades (E1 [8.3\%] < E4 [15.8\%] < M1 [22.9\%] < H1 [25.3\%], $p<0.001)$. However, there was no significant difference in the prevalence of malocclusion in each grade group for the period $(p>0.05)$ without significant correlation (E1, $\rho=0.129 ; \mathrm{E} 4, \rho=-0.495 ; \mathrm{M} 1, \rho=0.406 ; \mathrm{H} 1, \rho=-0.383$; all $p>0.05)$. The prevalence of malocclusion within each grade group over the six-year period was more prominent in the female $(p<0.0001)$. Conclusions: Further studies are necessary to modify the malocclusion assessment method to account for specific types of malocclusion in pre-adolescent and adolescent students.
\end{abstract}

[Korean J Orthod 2020;50(3):197-205]

Key words: Prevalence of malocclusion, Nationwide oral health examination, Malocclusion assessment, Preadolescent and adolescent students

Received September 3, 2019; Revised December 6, 2019; Accepted December 9, 2019.

Corresponding author: Seung-Hak Baek.

Professor, Department of Orthodontics and Dental Research Institute, School of Dentistry, Seoul National University, 101 Daehak-ro, Jongno-gu, Seoul 03080, Korea.

Tel +82-2-2072-3952 e-mail drwhite@unitel.co.kr

How to cite this article: Hong M, Kyung HM, Park HS, Yu WJ, Baek SH. Estimation of the prevalence of malocclusion on the basis of nationwide oral health examinations of pre-adolescent and adolescent students during 2012-2017. Korean J Orthod 2020;50:197-205.

(C) 2020 The Korean Association of Orthodontists.

This is an Open Access article distributed under the terms of the Creative Commons Attribution Non-Commercial License (http://creativecommons.org/licenses/by-nc/4.0) which permits unrestricted non-commercial use, distribution, and reproduction in any medium, provided the original work is properly cited. 


\section{INTRODUCTION}

The low birth rate in Korea, Republic (KR) has recently become a serious social issue. According to KR statistics, the population of children is projected to decrease from $7,030,000$ persons $(13.8 \%)$ in 2015 to $5,980,000$ persons $(11.3 \%)$ in 2035 , and to $4,130,000$ persons $(9.6 \%)$ in 2065. Furthermore, the Korean Dental Association reported that 1,395 orthodontic specialists have been certified since $2008 .{ }^{2}$ Therefore, there are increasing concerns regarding a potential reduction in the demand for orthodontic treatment in the future and increased competition among orthodontists under the new professionalism system.

Epidemiological studies are useful for measuring the distribution of specific diseases in the population and for planning and evaluating healthcare services, such as professional education and the doctor-to-patient ratio. The estimated prevalence of malocclusion in a particular population can provide basic information about the supply and demand of professional health care providers. Several studies have attempted to measure the orthodontic treatment needs and estimate the prevalence of malocclusion in specific communities, yielding descriptive data for the distribution of individuals seeking orthodontic treatment in specific populations. ${ }^{3-6}$

In KR, numerous epidemiologic studies have been conducted using community surveys, ${ }^{7,8}$ longitudinal dental hospital data analyses, ${ }^{9-17}$ and longitudinal local dental clinic data analyses. ${ }^{18,19}$ However, these studies share a common limitation in that they are not based on nationwide sampling or survey data. In this regard, the Ministry of Education, KR has conducted an annual oral health examination for pre-adolescent and adolescent students since 2008, and the data from this survey can be reorganized as a secondary dataset for estimating the prevalence of malocclusion. To our knowledge, there has been no published study including nationwide assessment of malocclusion in pre-adolescent and adolescent students. Therefore, the purpose of this study was to investigate the prevalence of malocclusion in relation to grade, sex, and year in pre-adolescent and adolescent students of KR during 2012-2017.

\section{MATERIALS AND METHODS}

\section{Subjects}

In this study, for the purpose of homogeneity of sampling methods, the analyzed data were based on oral health examinations for pre-adolescent and adolescent students conducted from 2012 to 2017. For stratified sampling, the primary unit was "school" and the secondary unit was "classroom". Selection of "school" was based on probability proportional to size sampling.
For the secondary unit, complete enumeration for one classroom of the primary unit school was fulfilled. For example, in 2017, a total of 764 schools, including 250 elementary schools, 254 middle schools, and 260 high schools, were selected.

The final sample was extracted from one whole class room of each school: the first grade (E1; student age, 6-7 years) and fourth grade (E4; age, 9-10 years) of elementary schools, the first grade of middle schools (7th grade, M1; age, 12-13 years), and the first grade of high schools (10th grade, $\mathrm{H} 1$; age, 15-16 years). The reason of selecting these grades was that the dental ages at $\mathrm{E} 1, \mathrm{E} 4, \mathrm{M} 1$, and $\mathrm{H} 1$ might represent the early mixed dentition stage, late mixed dentition, early permanent dentition, and permanent dentition, respectively. The final samples consisted of 165,996 students including 33,743 students for E1, 33,856 students for E4, 47,051 students for M1, and 51,346 students for H1 (Table 1). ${ }^{20}$ This study was reviewed and approved by the Institutional Review Board of the Kyungpook National University Dental Hospital (KNUDH-2009-11-04-00).

\section{Assessment of malocclusion}

Each student in the final sample visited a dental clinic for an oral health examination that included evaluation of dental caries, missing teeth, soft tissue disease, malocclusion, and oral hygiene (Figure 1). Assessment of malocclusion was carried out by dentists' judgments and divided into "no malocclusion (N-M)," "needs orthodontic treatment (N-OTx)," and "under orthodontic treatment (U-OTx)." The criteria for assigning "N-OTx" and "N-M" were the presence of a class 1 occlusion and normal overbite/overjet, respectively. The number of students with malocclusion was calculated as the sum of $\mathrm{N}-\mathrm{OTx}$ and U-OTx cases.

\section{Statistical analysis}

This secondary longitudinal dataset was reorganized to analyze the prevalence of malocclusion according to grade, sex, and year-by-year differences. Descriptive statistics, two-way analysis of variance (ANOVA), and Pearson correlation analysis were performed for statistical analysis. Two-way ANOVA was designed to assess the interrelationship of the variables grades and sex on the prevalence of malocclusion. IBM SPSS Statistics ver. 23.0 (IBM Corp., Armonk, NY, USA) was used. A $p$-value of < 0.05 was considered significant.

\section{RESULTS}

\section{The estimated prevalence of major oral diseases}

The mean prevalence of dental caries was $27.6 \%$ (range, 23.6-30.9\%), followed by malocclusion (mean, 18.7\%; range, 16.9-20.3\%) and periodontitis (mean, 


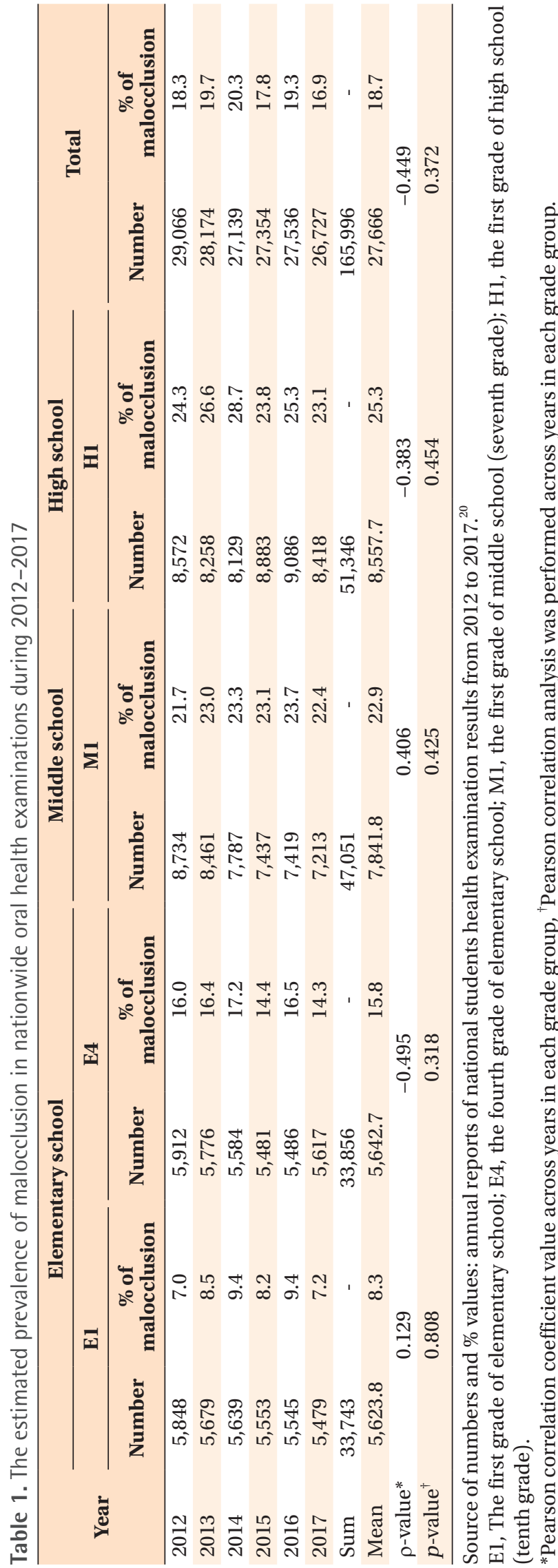

14.6\%; range, $13.2-17.0 \%$ ) (Figure 2) ${ }^{20}$

Year-by-year changes in the prevalence of malocclusion

There was no significant correlation for each grade group across all years $(\mathrm{E} 1, \rho=0.129 ; \mathrm{E} 4, \rho=-0.495$; $\mathrm{M} 1, \rho=0.406 ; \mathrm{H} 1, \rho=-0.383$; all $p>0.05$; Table 1). Therefore, the prevalence of malocclusion in each grade group did not present annual differences.

\section{Changes in the prevalence of malocclusion according to sex* grade}

A two-way ANOVA was conducted to compare the prevalence of malocclusion in relation to sex and grades, considering type 11 error. Significant main effects were observed for both grade ( $f=327.151, p<0.0001)$ and sex ( $f=53.584, p<0.0001)$. However, grade*sex did not show a significant interactive effect $(f=1.275, p=$ 0.296) (Table 2). ${ }^{20}$

\section{Changes in the prevalence of malocclusion according to sex and grades}

The mean prevalence of malocclusion increased with grade $(\mathrm{E} 1[8.3 \%]<\mathrm{E} 4[15.8 \%]<\mathrm{M} 1[22.9 \%]<\mathrm{H} 1$ [25.3\%], $p<0.001$; Table 2). Thus, higher grades corresponded to a higher prevalence of malocclusion. Female participants showed a higher prevalence of malocclusion than did male participants ( $p<0.0001$; Table 2). However, there was no significant correlation for this relationship in each grade during the study period (all $p>0.05$, Table 1). Therefore, it can be stated that the prevalence of malocclusion tended to greater in the female participants in each grade group over the six-year study period.

\section{DISCUSSION}

\section{The estimated prevalence of major oral diseases}

In this study, $18.7 \%$ of subjects had malocclusion, which showed a prevalence lower than that of dental caries $(27.6 \%)$ but higher than that of periodontitis (14.6\%) (Figure 2). While the prevalence of dental caries reduced from 2012 to 2017, the prevalences of malocclusion and periodontitis remained steady during these years (Figure 2).

There is some controversy regarding the relationships between malocclusion and other oral diseases. Arora and Bhateja ${ }^{21}$ insisted that malocclusion did not have a significant effect on the prevalence of dental caries and periodontitis among 12-year-old school children. However, a positive correlation between the degree of malocclusion severity and the existence of dental caries was reported in the primary dentition by Disha et al. ${ }^{22}$ and among students aged 11-15 years by Baskaradoss et al. ${ }^{23}$ This relationship should be investigated using more so- 


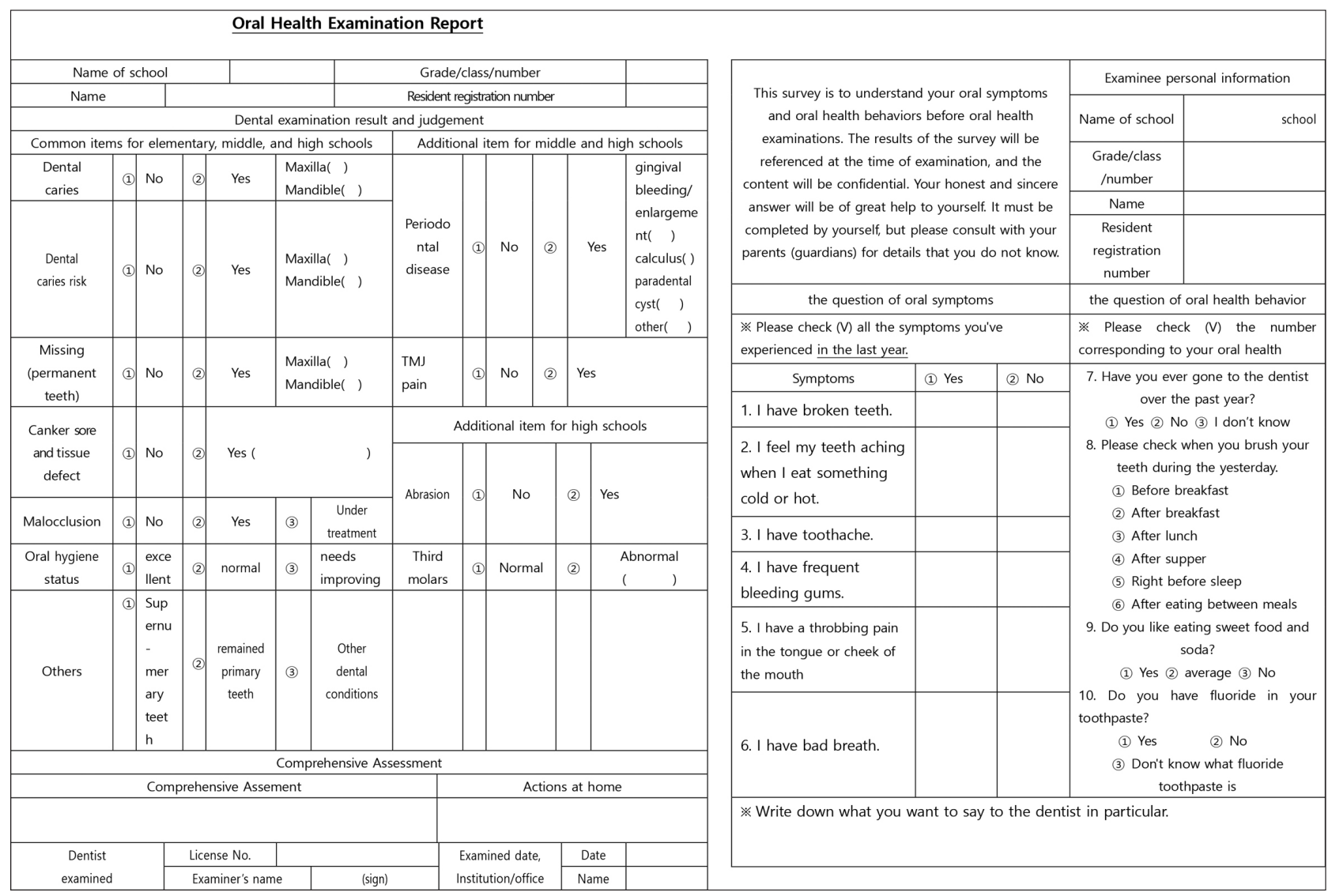

Figure 1. Oral health examination form for pre-adolescent and adolescent students provided by the Ministry of Education, Korea.

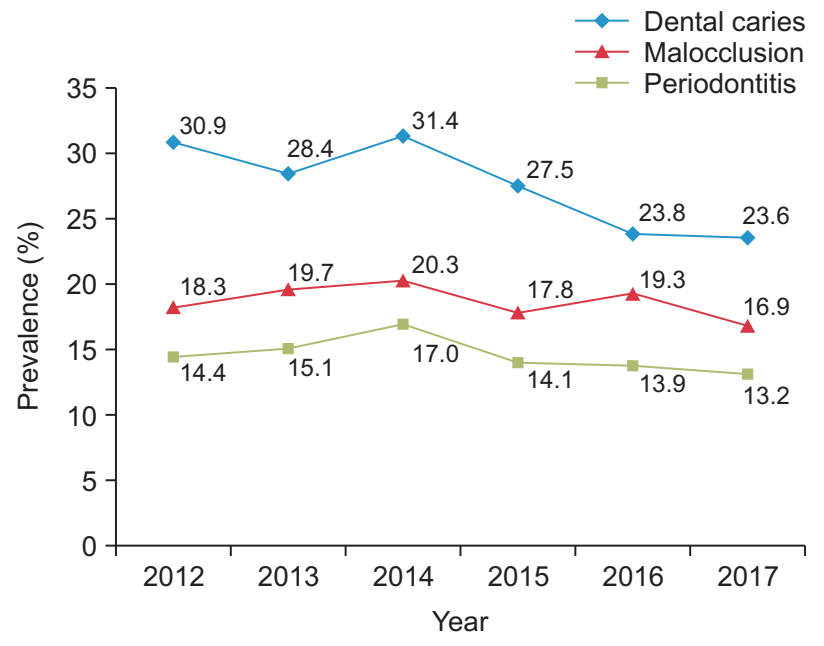

Figure 2. Trend of changes in the estimated prevalence of major oral diseases across nationwide oral health examinations during 2012-2017. The stratified and extracted samples consisted of students in the first grade (elementary school), fourth grade (elementary school), seventh grade (middle school), and tenth grade (high school).

Source of origin: annual reports of national students health examination results from 2012 to $2017 .^{20}$ phisticated malocclusion assessment methods and larger sample sizes with nationwide oral health examination.

\section{The estimated prevalence of malocclusion}

The prevalence of malocclusion in this study was estimated to be $18.7 \%$. However, the prevalence of malocclusion among growing children has been reported to range from $39-93 \% .^{22,24-26}$ This discrepancy can be attributed to differences in ethnicity, age, and the criteria and methodologies used for assessment. In terms of the criteria and methodologies used for assessment, previous studies used Angle's classification, index of orthodontic treatment need (10TN), dental esthetic index (DAI), and treatment priority index $(\mathrm{TPI})^{24,27}$; while the present study used three criteria categorized as $\mathrm{N}-\mathrm{M}, \mathrm{N}-\mathrm{OTx}$, and U-OTx (Figure 1).

\section{Comparison of the estimated prevalence of malocclusion in the Korean population}

In Table 3, we have summarized the results from previous Korean epidemiologic studies on the distribution of malocclusion type or utilization of orthodontic treatment services. Although the majority of previous 
Table 2. Comparison of the estimated prevalence of malocclusion with respect to grade and sex

\begin{tabular}{|c|c|c|c|}
\hline & Group & & Value* \\
\hline \multirow[t]{8}{*}{ Elementary school } & E1 $(33,743)$ & Number & $5,623.8$ \\
\hline & & Total (\%) & 8.3 \\
\hline & & Male (\%) & 7.4 \\
\hline & & Female (\%) & 9.2 \\
\hline & E4 $(33,856)$ & Number & $5,642.7$ \\
\hline & & Total (\%) & 15.8 \\
\hline & & Male (\%) & 14.3 \\
\hline & & Female (\%) & 17.4 \\
\hline \multirow[t]{4}{*}{ Middle school } & M1 $(47,051)$ & Number & $7,841.8$ \\
\hline & & Total (\%) & 22.9 \\
\hline & & Male (\%) & 21.0 \\
\hline & & Female (\%) & 24.9 \\
\hline \multirow[t]{4}{*}{ High school } & H1 $(51,346)$ & Number & $8,557.7$ \\
\hline & & Total (\%) & 25.3 \\
\hline & & Male (\%) & 23.3 \\
\hline & & Female (\%) & 27.0 \\
\hline \multirow[t]{4}{*}{ Total $(165,996)$} & & Number & 27,666 \\
\hline & & Total (\%) & 18.7 \\
\hline & & Male (\%) & 16.5 \\
\hline & & Female (\%) & 19.6 \\
\hline$p$-value & & & $\begin{array}{l}\text { Grade: } \mathrm{E} 1<\mathrm{E} 4<\mathrm{M} 1<\mathrm{H} 1, p<0.0001 ; \text { Sex: Male } \\
\quad<\text { Female, } p<0.0001 ; \text { Grade*Sex, } p=0.296\end{array}$ \\
\hline
\end{tabular}

$p$-value from two-way analysis of variance test regarding two factors including four grade levels and sex.

E1, The first grade of elementary school; E4, the fourth grade of elementary school; M1, the first grade of middle school (seventh grade); $\mathrm{H} 1$, the first grade of high school (tenth grade).

*Secondary data based on raw data from annual reports of national students health examination results from 2012 to $2017 .{ }^{20}$

studies used Angle's classification to determine malocclusion type, ${ }^{7,9-19}$ only one study used the malocclusion indices (handicapping labiolingual deviation; TPI; and handicapped malocclusion assessing record). ${ }^{8}$ However, these previous studies had inevitable limitations, including small sample sizes, specific hospital patients or local clinic patients, and inability to calculate the prevalence of malocclusion.

The prevalence of malocclusion reported by Suhr et al. ${ }^{7}$ was much higher than that noted in this study (61.2 vs. $18.7 \%$ ). Although the study by Suhr et al. ${ }^{7}$ was the only study that reported the prevalence of malocclusion in Korean students among previous Korean epidemiological studies, they regarded the sum of cases showing Angle's class 1 (45.7\%), class 11 (7.6\%), and class 111 (7.9\%) cases as those requiring orthodontic treatment. However, a high prevalence of malocclusion on the basis of Angle's classification did not necessarily indicate the needs for orthodontic treatment. ${ }^{26}$ Furthermore, the approach of counting class 1 malocclusion cases as those requiring orthodontic treatment might result in over-estimation of the prevalence of malocclusion.

\section{Changes in the prevalence of malocclusion according to grades}

In the present study, the prevalence of malocclusion increased with grades $(8.3 \%$ for E1, $15.8 \%$ for E4, $22.9 \%$ for $\mathrm{M} 1$, and $25.3 \%$ for $\mathrm{H} 1$; $\mathrm{E} 1<\mathrm{E} 4<\mathrm{M} 1<\mathrm{H} 1$, $p<0.001$; Table 2). These findings indicate that the number of students with malocclusion in the permanent dentition was higher than those in the mixed dentition $(\mathrm{M} 1+\mathrm{H} 1, \mathrm{n}=98,397 / 165,996$ [59.3\%] vs. $\mathrm{E} 1+\mathrm{E} 4, \mathrm{n}=$ 67,599/165,996 [40.7\%]; Table 1).

For malocclusion in the mixed dentition stage, such as those encountered in E1 and E4, the skeletal malocclusion type might primarily influence the type of orthodontic treatment required. However, for malocclusion in the permanent dentition stage, such as those observed in $\mathrm{M} 1$ and $\mathrm{H} 1$, both skeletal and dental malocclusion types might influence the type of orthodontic 
Table 3. Summary of previous epidemiologic studies on malocclusion assessment in Korea

\begin{tabular}{|c|c|c|c|c|c|c|c|}
\hline \multirow[b]{2}{*}{ Author (year) } & \multirow[b]{2}{*}{ Assessment } & \multirow[b]{2}{*}{ Sample } & \multirow[b]{2}{*}{ Size } & \multirow[b]{2}{*}{ Prevalence (\%) } & \multicolumn{3}{|c|}{ Included as variables } \\
\hline & & & & & $\begin{array}{c}\text { Angle } \\
\text { classification }\end{array}$ & Sex & Age \\
\hline Suhr et al. ${ }^{7}(1984)$ & $\begin{array}{l}\text { Angle } \\
\text { classification }\end{array}$ & $\begin{array}{l}\text { 7-22 year old students in } \\
\text { Seoul }\end{array}$ & 8,989 & 61 & Yes & Yes & Yes \\
\hline Sohn et al. ${ }^{8}$ (1993) & $\begin{array}{l}\text { HLD, TPI, } \\
\text { and HMAR }\end{array}$ & $\begin{array}{l}\text { Elementary students from } \\
\text { Seoul, Gwangju, Hwasun, } \\
\text { and Anyang }\end{array}$ & 649 & Not applicable & No & Yes & No \\
\hline Kwon et al..$^{9}(1989)$ & $\begin{array}{l}\text { Angle } \\
\text { classification }\end{array}$ & $\begin{array}{l}\text { Kyungpook National } \\
\text { University Dental Hospital }\end{array}$ & 1,795 & Not applicable & Yes & Yes & Yes \\
\hline Yang $^{10}(1995)$ & $\begin{array}{l}\text { Angle } \\
\text { classification }\end{array}$ & $\begin{array}{l}\text { Seoul National University } \\
\text { Dental Hospital }\end{array}$ & 6,788 & Not applicable & Yes & Yes & Yes \\
\hline Baik et al. ${ }^{11}$ (1995) & $\begin{array}{l}\text { Angle } \\
\text { classification }\end{array}$ & $\begin{array}{l}\text { Yonsei University Dental } \\
\text { Hospital }\end{array}$ & 2,155 & Not applicable & Yes & Yes & Yes \\
\hline Yu et al. ${ }^{12}$ (1999) & $\begin{array}{l}\text { Angle } \\
\text { classification }\end{array}$ & $\begin{array}{l}\text { Yonsei University Dental } \\
\text { Hospital }\end{array}$ & 9,159 & Not applicable & Yes & Yes & Yes \\
\hline $\begin{array}{l}\text { Hwang et al. }{ }^{13} \\
\text { (2001) }\end{array}$ & $\begin{array}{l}\text { Angle } \\
\text { classification }\end{array}$ & $\begin{array}{l}\text { Chosun University Dental } \\
\text { Hospital }\end{array}$ & 3,070 & Not applicable & Yes & Yes & Yes \\
\hline Im et al..$^{14}(2003)$ & $\begin{array}{l}\text { Angle } \\
\text { classification }\end{array}$ & $\begin{array}{l}\text { Seoul National University } \\
\text { Dental Hospital }\end{array}$ & 676 & Not applicable & Yes & Yes & Yes \\
\hline $\begin{array}{l}\text { Chung and Lee }{ }^{15} \\
\text { (2006) }\end{array}$ & $\begin{array}{l}\text { Angle } \\
\text { classification }\end{array}$ & $\begin{array}{l}\text { Yeungnam University } \\
\text { Hospital }\end{array}$ & 993 & Not applicable & Yes & Yes & Yes \\
\hline Yoon $^{16}(2008)$ & $\begin{array}{l}\text { Angle } \\
\text { classification }\end{array}$ & $\begin{array}{l}\text { Dankook University Dental } \\
\text { Hospital }\end{array}$ & 4,043 & Not applicable & Yes & Yes & Yes \\
\hline Jung $^{18}(2009)$ & $\begin{array}{l}\text { Angle } \\
\text { classification }\end{array}$ & Private clinics & 1,620 & Not applicable & Yes & Yes & Yes \\
\hline Piao et al. ${ }^{17}(2016)$ & $\begin{array}{l}\text { Angle } \\
\text { classification }\end{array}$ & $\begin{array}{l}\text { Yonsei University Dental } \\
\text { Hospital }\end{array}$ & 7,476 & Not applicable & Yes & Yes & Yes \\
\hline Choi $^{19}(2017)$ & $\begin{array}{l}\text { Angle } \\
\text { classification }\end{array}$ & Private clinic & 1,254 & Not applicable & Yes & Yes & Yes \\
\hline This study & $\begin{array}{l}\text { Subjective } \\
\text { assessment }\end{array}$ & Nationwide sample & 165,996 & 18.7 & No & Yes & Yes \\
\hline
\end{tabular}

HLD, Handicapping labiolingual deviation; TPI, treatment priority index; HMAR, handicapped malocclusion assessing record.

treatment required. Therefore, in the early and late mixed dentition period (E1 and E4), growth modification of skeletal malocclusion and interceptive/preventive orthodontic treatment for dental malocclusion should be considered. However, in the early permanent dentition and permanent dentition periods ( $\mathrm{M} 1$ and $\mathrm{H} 1$ ), one out of four to five students showed malocclusion. This could be attributed to the following reasons: (1) skeletal malocclusion worsens with age, and (2) dental dysplasia, such as protrusion, abnormal overjet, and deep/open bite are apparent in the development of the permanent dentition.

\section{Changes in the prevalence of malocclusion according to sex}

In the present study, the female group showed a dominant pattern in the prevalence of malocclusion over the male group in each grade group, regardless of year (19.6\% vs.16.5\%, $p<0.0001$; Table 2). However, Suhr et al. ${ }^{7}$ reported no significant difference in malocclusion prevalence between males and females among 7to 22-year-old Korean students. This variance might be due to differences in the assessment methods and geographic regions: Suhr et al. ${ }^{7}$ considered the sum of cases showing Angle's class 1 (45.7\%), 11 (7.6\%), and 111 (7.9\%) as those requiring orthodontic treatment and conducted their study in a single community (Seoul); in contrast, this study considered the sum of those categorized as "N-OTx" and "U-OTx" as those requiring orthodontic treatment and was conducted nationwide. 
Table 4. Suggested criteria for malocclusion assessment

\begin{tabular}{|c|c|c|c|c|}
\hline \multicolumn{2}{|r|}{ Component } & \multicolumn{3}{|c|}{ Assessment criteria } \\
\hline \multicolumn{2}{|c|}{ History of previous orthodontic treatment } & Removable appliance & Extraoral appliance & Fixed appliance \\
\hline \multirow[t]{4}{*}{ Facial } & Profile & Convex & Straight & Concave \\
\hline & Facial type & Brachy & Meso & Dolicho \\
\hline & Asymmetry & Symmetry & Asymmetry & - \\
\hline & Nasolabial angle & Obtuse & Normal & Acute \\
\hline \multirow[t]{8}{*}{ Dental } & Antero-posterior relationship & Class I & Class II & Class III \\
\hline & Anterior crossbite & Yes & No & \\
\hline & Vertical relationship & Open & Normal & Deep \\
\hline & Posterior crossbite & Unilateral crossbite & Normal & Unilateral scissor bite \\
\hline & & Bilateral crossbite & & Bilateral scissor bite \\
\hline & Arch length discrepancy & Crowding & Normal & Spacing \\
\hline & Upper incisor & Labioversion & Normal & Linguoversion \\
\hline & Lower incisor & Labioversion & Normal & Linguoversion \\
\hline
\end{tabular}

Suggestion of new assessment method for Korean oral health examination

The main objectives of malocclusion assessment in oral health examinations are to screen patients who may potentially require orthodontic treatment and to recommend appropriate orthodontic treatment methods and appliances depending on their malocclusion types. However, the current malocclusion assessment method in Korean oral health examinations (Figure 1) has some limitations as follows: (1) Since individual occlusal development stage can vary even within the same grade or age, it is necessary to obtain actual examination recordings or radiographic images of the sample when obtaining the secondary data set. (2) It cannot explain the malocclusion types including the skeletal or dental origin. (3) It cannot reveal the specific reasons underlying the need of orthodontic treatment. (4) When the subjects who received orthodontic treatment previously might have unsolved problems, unfavorable growth potential, or relapse, it is necessary to decide whether they should be classified as "N-M" or "N-OTx."

Alajlan et al. ${ }^{26}$ classified the malocclusion type in a clinically simple and practical manner: openbite, crossbite, and scissor bite. Therefore, it is necessary to revise the oral health examination form to allow classification of the problems or malocclusion types. Thus, we would like to propose additions to the oral health examination form to obtain further information (Table 4). The revised oral health examination form consists of three major components, which are "History of previous orthodontic treatment," including "Facial" and "Dental"; "History of previous orthodontic treatment," including removable, extraoral, or fixed appliance; "Facial component" include "Profile," "Facial type," "Asymmetry," and
"Nasolabial angle"; and "Dental component" including "Antero-posterior relationship," "Anterior crossbite," "Vertical relationship," "Posterior crossbite," "Arch length discrepancy," and "inclination of the upper and lower incisors." Therefore, after examiners check all the components comprehensively and rule them out one by one, they can refer their examinee to the specialists at an appropriate time. Appropriate timely referral is critical for the success of orthodontic treatment. In addition, use of cephalometric or panoramic radiographs can increase the reliability of malocclusion assessment.

Although the absolute demand for orthodontic treatment in the growing children population in Korea might decrease in the next few decades, the orthodontic treatment needs for adults and/or elderly people population might increase due to concerns over facial and dental esthetics. Therefore, nationwide examinations including assessment of malocclusion types and orthodontic treatment needs of adults should be considered in future studies.

\section{CONCLUSION}

Although significant information about the prevalence of malocclusion could be obtained from nationwide oral health examinations, further studies are necessary to modify the malocclusion assessment methods for providing specific type of malocclusion data in pre-adolescent and adolescent students.

\section{CONFLICTS OF INTEREST}

No potential conflict of interest relevant to this article was reported. 


\section{ACKNOWLEDGEMENTS}

This research was supported by Korean Association of Orthodontists Research Fund, 2017.

\section{REFERENCES}

1. National Assembly Budget Office. Major results and implications on economic policy based on population projection in Korea (2015-2065) [Internet]. Seoul: National Assembly Budget Office; 2017 Jan [cited 2018 Nov 20]. Available from: https:// www.nabo.go.kr/Sub/01Report/09_Board.jsp?fun $\mathrm{c}=$ view tfuncSUB $=$ etcurrentPageSUB $=0$ ctpageSize SUB $=10$ ctkey_typeSUB $=$ ctkeySUB $=$ Ctsearch_start_ dateSUB $=$ Ctsearch_end_dateSUB $=C$ targ_id $=0$ ctbid $=63$ trbid $=0$ etrid $x=0$ etbidSUB $=0$ ttcid $1=0 \& \operatorname{cid} 2=0$ Etcid $3=0$ etcid $4=0$ etcid $5=0$ etcid $6=0 \& \operatorname{cid} 7=0$ targ cid $1=0$ ttarg_cid $2=0$ ttarg_class_id $=0$ tcurrentPage $=$ $3 \&$ tpageSize $=10 \mathrm{t}$ pagePerBlock $=0 \&$ tnowBlock $=3 \& \mathrm{tk}$ ey_type $=$ Ctkey $=$ Ctsearch_start_date $=$ Ctsearch_end_ date $=$ Ctclass_id $=0$ CtsortBy $=$ CtascOrDesc $=$ Ctbidx $=618$ $8 c t i d x=61884$ treg_name $=\% \mathrm{EA} \% \mathrm{~B} 2 \% \mathrm{BD} \% \mathrm{EC} \% \mathrm{A0} \% 9$ C\%EC\%A0\%95\%EC\%B1\%85\%EB\%B6\%84\%EC\%84 $\% 9 D \% E A \% B 3 \% B C$.

2. Chun SH. The advent of age of 10,000 dental specialists in coming year [Internet]. Seoul: Daily Dental Press of Korean Dental Association; 2019 Jul 5 [cited 2019 Aug 5]. Available from: http://www.dailydental.co.kr/news/article.html?no=106811.

3. Brook PH, Shaw WC. The development of an index of orthodontic treatment priority. Eur J Orthod 1989;11:309-20.

4. Shaw WC, Richmond S, O'Brien KD. The use of occlusal indices: a European perspective. Am J Orthod Dentofacial Orthop 1995;107:1-10.

5. Burden DJ, Pine CM, Burnside G. Modified IOTN: an orthodontic treatment need index for use in oral health surveys. Community Dent Oral Epidemiol 2001;29:220-5.

6. Grippaudo C, Paolantonio EG, Deli R, La Torre G. Validation of the Risk of Malocclusion Assessment (ROMA) index. Eur J Paediatr Dent 2007;8:136-42.

7. Suhr CH, Nahm DS, Chang Yl. Epidemiologic study of the prevalence of malocclusion in Korean. Korean J Orthod 1984;14:33-7.

8. Sohn BW, Hwang CJ, Hwang HS. Modality of malocclusion according to regional difference using HLD (handicapping labiolingual deviation), TPI (Treatment priority index) and HMAR (handicapped malocclusion assessing record). Korean J Orthod 1993;23:17-35.

9. Kwon OW, Kyung HM, Gok DB, Sun JH, Park DW. The distribution and trend of malocclusion patients visited at department of orthodontics. Korean J Orthod 1989;19:35-48.

10. Yang WS. The study on the orthodontic patients who visited department of orthodontics, Seoul National University Hospital during last 10 years (1985-1994). Korean J Orthod 1995;25:497-509.

11. Baik HS, Kim KH, Park Y. The distributions and trends in malocclusion patients- a 10 year study of 2155 patients from YDSH. Korean J Orthod 1995; 25:87-100.

12. Yu HS, Ryu YK, Lee JY. A study on the distributions and trends in malocclusion patients from department of orthodontics, college of dentistry, Yonsei university. Korean J Orthod 1999;29:267-76.

13. Hwang MS, Yoon YJ, Kim KW. An epidemiologic study on the orthodontic patients who visited department of orthodontics, Chosun University Dental Hospital last 10 years (1990 1999). Korean J Orthod 2001;31:283-300.

14. Im DH, Kim TW, Nahm DS, Jang Yl. Current trends in orthodontic patients in Seoul National University Dental Hospital. Korean J Orthod 2003;33:63-72.

15. Chung SH, Lee HK. Trends in malocclusion patients of Yeungnam University Hospital. Yeungnam Univ J Med 2006;23:71-81.

16. Yoon HJ. (A) study on the distributions and trends in malocclusion patient who were treated in department of orthodontics, Dankook University Dental Hospital during the last 20 years [MS thesis]. Cheonan: Dankook University; 2008.

17. Piao Y, Kim SJ, Yu HS, Cha JY, Baik HS. Five-year investigation of a large orthodontic patient population at a dental hospital in South Korea. Korean J Orthod 2016;46:137-45.

18. Jung $\mathrm{MH}$. Current trends in orthodontic patients in private orthodontic clinics. Korean J Orthod 2009;39:36-42.

19. Choi YH. Current trends in of orthodontic patients in private orthodontic clinic in Daegu [MS thesis]. Daegu: Kyungpook National University; 2017.

20. Students' Health Information Center. Online archive of annual reports on health examination of national student sample [Internet]. Seoul: Ministry of Education; 2009 May [updated 2019 Nov 13; cited 2018 Jul 20]. Available from: http:// www.schoolhealth.kr/web/srs/selectPublicDatalist. do?sMenuld=0100008900.

21. Arora G, Bhateja S. Prevalence of dental caries, periodontitis, and oral hygiene status among 12-yearold schoolchildren having normal occlusion and malocclusion in Mathura city: a comparative epidemiological study. Indian J Dent Res 2015;26:48-52.

22. Disha P, Poornima P, Pai SM, Nagaveni NB, Roshan NM, Manoharan M. Malocclusion and dental caries 
experience among 8-9-year-old children in a city of South Indian region: a cross-sectional survey. J Educ Health Promot 2017;6:98.

23. Baskaradoss JK, Geevarghese A, Roger C, Thaliath A. Prevalence of malocclusion and its relationship with caries among school children aged 11-15 years in southern India. Korean J Orthod 2013;43:35-41.

24. Thilander B, Pena L, Infante C, Parada SS, de Mayorga C. Prevalence of malocclusion and orthodontic treatment need in children and adolescents in Bogota, Colombia. An epidemiological study related to different stages of dental development. Eur J
Orthod 2001;23:153-67.

25. Dimberg L, Lennartsson B, Arnrup K, Bondemark L. Prevalence and change of malocclusions from primary to early permanent dentition: a longitudinal study. Angle Orthod 2015;85:728-34.

26. Alajlan SS, Alsaleh MK, Alshammari AF, Alharbi SM, Alshammari AK, Alshammari RR. The prevalence of malocclusion and orthodontic treatment need of school children in Northern Saudi Arabia. J Orthod Sci 2019;8:10.

27. Agarwal A, Mathur R. An overview of orthodontic indices. World J Dent 2012;3:77-86. 